\title{
Binding Interactions of Murine Natural Killer Cells with the Fungal Target Cryptococcus neoformans
}

\author{
JUNEANN W. MURPHY, ${ }^{1 *}$ MICHELLE R. HIDORE, ${ }^{1}$ AND NASRIN NABAVI ${ }^{2}$ \\ Department of Microbiology and Immunology, University of Oklahoma Health Sciences Center, Oklahoma City, \\ Oklahoma 73190, ${ }^{1}$ and Department of Immunopharmacology, Hoffman-LaRoche, Nutley, New Jersey 07110
}

Received 11 September 1990/Accepted 23 January 1991

\begin{abstract}
Murine natural killer (NK) cells have been shown to inhibit the growth of the yeastlike organism Cryptococcus neoformans both in vivo and in vitro. An essential first step in NK cell-mediated damage of cryptococcal cells is the binding of the NK cell to the cryptococcal cell. The studies presented here focused on the binding event. Electron photomicrographs and three-dimensional reconstructions of NK cell- $C$. neoformans conjugates show that NK cells bind to cryptococci through many microvilli. This is in contrast to the broad membrane-membrane interactions which form the binding site of NK cell-YAC-1 tumor cell conjugates. NK cell binding to cryptococci is much slower than NK cell binding to YAC-1 targets. Maximal conjugate formation with cryptococcal targets is reached after $2 \mathrm{~h}$, whereas maximal conjugate formation with YAC-1 targets is obtained after $20 \mathrm{~min}$. Once maximum NK cell- $C$. neoformans conjugate formation is obtained, another $4 \mathrm{~h}$ is required before damage to the cryptococcal cells can be detected with the CFU assay. These data indicate that the binding and action of NK cells on $C$. neoformans cells requires considerably more time than is necessary for similar events to occur in the NK cell-tumor cell model. NK cell membrane integrity is necessary for NK cells to bind to tumor targets, since some disruption of membrane integrity with $0.1 \mathrm{M}$ dimethyl sulfoxide reduces conjugate formation and tumor cell lysis. In contrast, $0.1 \mathrm{M}$ dimethyl sulfoxide did not diminish NK cell binding to cryptococcal targets; however, it significantly reduced cryptococcal growth inhibition. Although we have observed several differences in NK cell binding to the cryptococcal target compared with NK cell binding to tumor cell targets, there are some similarities in binding interactions of NK cells with the two different targets. Disulfide bonding appears to play a role in the binding of NK cells to both targets, since $5 \mathrm{mM}$ 2-mercaptoethanol, a reagent that reduces disulfide bonds, prevented NK cells from binding to the tumor targets as well as the cryptococcal targets. Actin filaments, components of the cytoskeletal network, must be intact for NK cells to bind to YAC-1 cells or cryptococci. Taken together, our data confirm that binding of NK cells to the cryptococcal target is prerequisite to the stages that result in damage to the cryptococcal cell and that there are similarities and differences in NK cell-binding interactions with structurally different target cells.
\end{abstract}

Natural killer (NK) cells are a population of asialo $\mathrm{GM}_{1}{ }^{+}$ large granular lymphocytes (LGL), which are present in unimmunized animals and are characterized by their ability to lyse certain sensitive tumor cells through a nonphagocytic mechanism (28). This population of cells has been reported to contribute to innate cellular resistance against certain tumor and virus-infected cells, bacteria, fungi, and parasites (36). NK cell-mediated cytotoxicity of tumor cell targets has been extensively studied and is relatively well defined. This phenomenon can be separated into five sequential stages which include: (i) binding, (ii) programming of the NK cell, (iii) delivery of the lethal hit, (iv) killer cell-independent lysis, and (v) recycling $(15,16,34)$.

Although binding of NK cells to tumor targets is an essential first step in the sequence of stages that culminate in lysis of the sensitive target cells, it does not always lead to lysis of the target (36). Thus, there must be multiple receptors involved in recognition, binding, and signaling, and those receptors have not as yet been clearly defined (36). Despite the fact that specific binding receptors have not been identified, several features of interactions between NK cells and tumor cells have been established. The attachment region between NK cells and sensitive tumor targets consists of large areas of membrane-membrane association in the

\footnotetext{
${ }^{*}$ Corresponding author.
}

area of the interdigitating membranes of the two cells (32). The binding of NK effector and tumor target cells is a reversible interaction (35), and once the NK cell has delivered the lethal hit, it recycles to another target cell $(19,37)$. Formation of stable conjugates occurs within 20 min after mixing NK cells with sensitive tumor targets, and an additional $5 \mathrm{~min}$ is required for lysis of the target cell (32). NK cell-tumor cell conjugate formation is dependent on the membrane and cytoskeletal integrity of the effector cells (16, $31)$ and the presence of $\mathbf{M g}^{2+}(14,32)$ but is independent of temperature (32). Disulfide bonding also appears to be important in conjugate formation since 2-mercaptoethanol (2ME) blocks binding of NK cells to tumor targets (16).

We have previously shown that murine NK cells, through a direct nonphagocytic interaction, can limit the growth of a mycotic disease-causing agent, Cryptococcus neoformans $(10-13,24,26,27)$. As with the tumor cell targets, binding of the NK cells to cryptococcal cells appears to be an essential first step that precedes NK cell-mediated damage to the cryptococcal cells $(12,27)$. Only a limited amount of information is available regarding the binding of NK cells to cryptococci. Our earlier studies have demonstrated that $\mathrm{Mg}^{2+}$ is required for the binding of murine NK cells to cryptococcal target cells just as it is necessary for binding of NK cells to tumor cell targets (12). In addition, we have shown that temperatures below $37^{\circ} \mathrm{C}$ do not adversely affect 
binding of NK cells to cryptococcal cells providing the time allowed for binding is not less than $2.5 \mathrm{~h}$ (12).

Since binding of NK cells to cryptococci appears to be an essential interaction which leads to destruction of the cryptococcal target cells $(12,27)$, it is desirable to gain a better understanding of this event. Investigations presented here focus on the binding event and provide additional information on (i) the physical characteristics of the NK cell interactions with cryptococci compared with NK cell binding to YAC-1 tumor targets, (ii) the kinetics of the binding of NK cells to cryptococci, (iii) the relationship of the time required for binding and the time required for inhibition of cryptococcal growth, and (iv) the effects of various pharmacologic agents on NK cell binding to cryptococci and the subsequent mediation of growth inhibition.

\section{MATERIALS AND METHODS}

Mice. Female CBA/J mice were obtained from Jackson Laboratories, Bar Harbor, Me. The animals were maintained in the University of Oklahoma (Norman and Oklahoma City) animal facilities until they were used for these studies at 8 to 10 weeks of age.

Reagents. EGTA [ethylene glycol-bis( $\beta$-aminoethyl ether)$\mathrm{N}, \mathrm{N}, \mathrm{N}^{\prime}, \mathrm{N}^{\prime}$-tetraacetic acid] $(2.5 \mathrm{mM}), \mathrm{MgCl}_{2}(2.5 \mathrm{mM})$, dimethyl sulfoxide (DMSO), and 2-ME were prepared in complete medium (CM) consisting of RPMI 1640 medium (GIBCO Laboratories, Grand Island, N.Y.) supplemented with $10 \%$ heat-inactivated fetal bovine serum, $100 \mathrm{U}$ of penicillin per $\mathrm{ml}$, and $100 \mu \mathrm{g}$ of streptomycin per $\mathrm{ml}$. Cytochalasins B and D were dissolved in DMSO and diluted in $\mathrm{CM}$, resulting in a final DMSO concentration of $0.12 \%$. The reagent concentrations indicated were the final concentrations of each reagent within the assay samples. All reagents were purchased from Sigma Chemical Co., St. Louis, Mo.

Fungal target. $C$. neoformans isolate $184 \mathrm{~A}$ was maintained on modified Sabouraud agar slants (25). After 3 days of growth at room temperature, blastoconidia were harvested, washed three times in sterile physiological saline, and adjusted to the desired cell concentration for each experiment with CM. Cell concentrations were based on hemacytometer counts and confirmed by determining the CFU on modified Sabouraud agar plates.

Effector cells. Murine splenic nylon wool-nonadherent (NWN) cells were isolated (17) and used as effector cells in certain assays or further enriched for NK cells on discontinuous Percoll gradients as previously described (27). Briefly, to obtain NK cell-enriched populations by Percoll fractionation, NWN cells were centrifuged on a five-step Percoll gradient (27). The cells with LGL morphology were collected from the two interfaces between the 30,50 , and $55 \%$ Percoll layers, pooled, and counted in a hemocytometer. Such cell populations were referred to as Percoll fraction 1 and 2 cells. We have previously shown that the asialo $\mathrm{GM}_{1}{ }^{+}$ cells in similar Percoll fractions formed conjugates with $C$. neoformans (27). When DMSO, 2-ME, or cytochalasins were used in the designated experiments, the number of viable effector cells was also determined at the end of the incubation period to assess the effects of the added reagents on the viability of the effector cells. Effector cells were counted as viable cells if they excluded trypan blue dye in the hemocytometer counts.

Cell preparation for SEM and TEM. Percoll fraction 1 and 2 cells were mixed with $C$. neoformans target cells at an effector-cell-to-target-cell ratio of $2: 1$ in $0.2 \mathrm{ml}$ of CM. After
$12 \mathrm{~h}$ of incubation at $37^{\circ} \mathrm{C}$ in $5 \% \mathrm{CO}_{2}$, the cell suspensions were washed with Hanks balanced salt solution (GIBCO), resuspended in $0.2 \mathrm{ml}$ of RPMI 1640 medium, and placed on acetate film (Eastman Kodak Co., Rochester, N.Y.) that was precoated with $0.1 \%$ poly-L-lysine (Sigma). The cell suspension was incubated on the acetate film for $1 \mathrm{~h}$ at $4^{\circ} \mathrm{C}$ to allow the cells to adhere to the film. The cells were fixed for $30 \mathrm{~min}$ at $4^{\circ} \mathrm{C}$ with $3 \%$ glutaraldehyde (vol/vol), $6 \%$ paraformaldehyde ( $\mathrm{vol} / \mathrm{vol})$, and $0.2 \%$ tannic acid (wt/vol) in $0.1 \mathrm{M}$ sodium phosphate buffer ( $\mathrm{pH}$ 7.4). The fixed cells were washed with three changes of $0.1 \mathrm{M}$ sodium phosphate buffer at $4^{\circ} \mathrm{C}$ and postfixed for $30 \mathrm{~min}$ at $4^{\circ} \mathrm{C}$ with $0.1 \mathrm{M}$ sodium phosphate buffer containing $1 \%$ osmium tetroxide (wt/vol) and $0.01 \%$ ruthenium red (wt/vol), which was used to preserve the cryptococcal capsule. Following three washes in $0.1 \mathrm{M}$ sodium phosphate buffer at $4^{\circ} \mathrm{C}$, the cells were dehydrated in a graded series of ethanol dilutions. For scanning electron microscopy (SEM), the preparations were critical point dried in an Autosamdri 814 with liquid $\mathrm{CO}_{2}$ and then coated thinly with gold-palladium (60:40) in a Hummer VI before being examined on a JEOL JSM-880 scanning electron microscope. The preparations to be subjected to transmission electron microscopy (TEM) were infiltrated with Spurr's low viscosity resin (33). After flat-embedding, the cells were serially sectioned into $100-\mathrm{nm}$ sections with a diamond knife on a Sorvall MT-6000 or a Reichart Ultracut ultramicrotome, and the thin sections were collected by the method of Galey and Nilsson (8). Thin sections were mounted on Formvar- and carbon-coated copper slot grids, stained with $0.5 \%$ uranyl acetate (wt/vol) and Reynold's lead citrate (30), and examined on a Zeiss $10 \mathrm{~A}$ electron microscope at 40 or $60 \mathrm{kV}$. The electron microscopy grade reagents and grids used to prepare the cells for electron microscopy were purchased from Electron Microscopy Sciences, Fort Washington, $\mathrm{Pa}$.

Three-dimensional reconstructions of NK cell- $C$. neoformans conjugates. Three-dimensional reconstructions of NK cell-cryptococci conjugates were prepared by tracing serial sections $(100 \mathrm{~nm})$ of each complete conjugate on a Summa Sketch Plus which transfers the data into the IBM PC-based Three Dimensional Reconstruction System of S. M. Royer and J. C. Kinnamon, University of Colorado, Boulder.

Assay for effector cell-target cell conjugate formation. Binding of effector cells to either $C$. neoformans or YAC-1 target cells was assessed by the procedure previously described $(12,27)$. Briefly, effector cells $\left(10^{6}\right)$, either splenic NWN cells or Percoll fraction 1 and 2 cells, were mixed with target cells $\left(5 \times 10^{5}\right)$ at an effector-cell-to-target-cell ratio of 2:1 in $\mathrm{CM}$ or in $2-\mathrm{ME}(1$ or $5 \mathrm{mM})$, DMSO $(0.01$ or $0.1 \mathrm{M})$, cytochalasin B $(1$ or $6 \mu \mathrm{g} / \mathrm{ml})$, or cytochalasin D $(1,2,4$, or $6 \mu \mathrm{g} / \mathrm{ml}$ ) diluted in CM. The effector cells were incubated with the target cells for either variable times or times determined to be optimal for maximum NK cell-target cell binding $\left(2 \mathrm{~h}\right.$ at $37^{\circ} \mathrm{C}$ in $5 \% \mathrm{CO}_{2}$ for cryptococcal target cells or $1 \mathrm{~h}$ with similar culture conditions for YAC-1 target cells). To facilitate counting of the NK cell-cryptococcal cell conjugates, those samples were stained with $0.25 \%$ alcian blue in serum-free RPMI 1640 medium. The cell suspensions were gently mixed by repeated pipetting just before removing a sample for counting. Each conjugate suspension was counted by light microscopy, and the percentage of effector cells bound to target cells was calculated by counting a minimum of 200 effector cells.

$C$. neoformans growth inhibition assay. To assess NK cell-mediated inhibition of $C$. neoformans growth, the assay previously described by Murphy and McDaniel was used 
(26). Briefly, $10^{6}$ splenic NWN cells or $10^{5}$ Percoll fraction 1 and 2 cells and $2 \times 10^{3}$ cryptococcal target cells suspended in CM were added to quadruplicate wells of flat-bottom, 96-well microtiter plates (Linbro Scientific Co., Hamden, N.Y.). Quadruplicate control wells contained cryptococcal target cells in CM. Both experimental and control well volumes were adjusted to $0.25 \mathrm{ml}$ with $\mathrm{CM}$ or with an appropriate dilution of the variable reagent (2-ME, DMSO, or cytochalasin B or D) in CM. When effects of 1 or $5 \mathrm{mM}$ 2-ME, 0.01 or $0.1 \mathrm{M}$ DMSO, 1 or $6 \mu \mathrm{g}$ of cytochalasin B per $\mathrm{ml}$, or $1,2,4$, or $6 \mu \mathrm{g}$ of cytochalasin D per $\mathrm{ml}$ were determined, cryptococcal controls containing the reagent being assessed were included to ascertain that the culture conditions alone were not inhibitory to cryptococcal growth. After incubating the plates for $18 \mathrm{~h}$ at $37^{\circ} \mathrm{C}$ in $5 \% \mathrm{CO}_{2}$, the content of each well was serially diluted in sterile physiological saline and plated in duplicate on modified Sabouraud agar. After 3 days of incubation at room temperature, CFU were enumerated and the percentage of cryptococcal growth inhibition was determined in accordance with the following formula: \% cryptococcal growth inhibition $=[($ mean control $\mathrm{CFU}-$ mean experimental CFU)/mean control CFU] $\times 100$.

YAC-1 cytolytic assay. To assay the level of splenic NK cell activity, we performed a standard assay measuring the ${ }^{51} \mathrm{Cr}$ released from YAC-1 target cells as previously described $(12,20)$. Briefly, $10^{6}$ splenic NWN effector cells and $2 \times 10^{4}{ }^{51} \mathrm{Cr}$-labeled YAC-1 tumor cells suspended in CM were added to quadruplicate wells of a 96-well, roundbottom microtiter plate. Spontaneous release samples contained YAC-1 cells in CM, whereas maximum release samples contained YAC-1 cells in $2 \mathrm{~N} \mathrm{HCl}$. The volume of experimental wells, spontaneous release wells, and maximum release wells was adjusted to $0.2 \mathrm{ml}$ with either $\mathrm{CM}$ or the variable reagent to be assayed appropriately diluted in CM. After $4 \mathrm{~h}$ of incubation at $37^{\circ} \mathrm{C}$ in $5 \% \mathrm{CO}_{2}, 0.1 \mathrm{ml}$ of each supernatant was collected from the wells and counted in a gamma counter (Beckman Instruments, Inc., Fullerton, Calif.). Numerous studies have demonstrated the percentage of ${ }^{51} \mathrm{Cr}$ released is a direct correlate of the percentage of cytotoxicity or lysis of YAC-1 target cells $(20,22)$. In the experiments in which the effects of a variable reagent on YAC-1 cytolysis were assessed, appropriate spontaneous release and maximum release control wells containing equivalent concentrations of the variable reagent as those used in the experimental wells were included. The percentage of ${ }^{51} \mathrm{Cr}$ released from YAC-1 target cells was calculated with the following formula: $\%{ }^{51} \mathrm{Cr}$ released $=[$ (counts per minute of experimental supernatant - counts per minute of spontaneous supernatant)/counts per minute of maximum supernatant] supernatant] $\times 100$. The ${ }^{51} \mathrm{Cr}$ release assays were performed in parallel with the cryptococcal growth inhibition assays in these studies to ascertain that the various culture conditions did not adversely affect the activity of the effector cells.

Statistical analysis. Means and standard errors of the means were calculated, and the two-tailed Student's $t$ test was used to analyze the data.

\section{RESULTS}

Comparison of the binding regions of NK cell- $C$. neoformans conjugates and NK cell-YAC-1 conjugates. SEMs of NK cell- $C$. neoformans conjugates show that NK cells bind to the cryptococcal cell by many microvilli (Fig. 1). From our observations of stereo-paired photomicrographs, it was obvious that the microvilli indicated by arrows in Fig. 1 were in intimate contact with the surface of the cryptococcal cell. We have examined several additional conjugates which were photographed so they could be viewed as stereo pairs and have seen NK cell microvilli in intimate contact with the surface of the cryptococcal cell in each of the conjugates. When TEM was used to compare the binding regions of NK cell- $C$. neoformans conjugates (Fig. 2) and NK cell-YAC-1 tumor cell conjugates (Fig. 3), again it was evident that there was a difference in the physical interactions of the NK cell with the two different target cells. The tips of the NK cell's microvilli made contact with the yeast cell surface (Fig. 2), and in some cases, we observed linear structures at the contact point of the NK cell microvilli and the surface of the cryptococcal cell (Fig. 2B, arrow). In contrast, NK cells associate with YAC-1 cells through broad membrane-membrane interactions (Fig. 3) (31).

Computer-generated three-dimensional reconstructions of NK cell- $C$. neoformans conjugates clearly demonstrate that the NK cell microvilli are physically associated with the cryptococcal cell through numerous small areas of contact (Fig. 4A). When the cryptococcal capsule was omitted from the three-dimensional images, the microvilli of the NK cell appeared to make contact with the cell wall (Fig. 4B).

Kinetics of NK cell- $C$. neoformans conjugate formation and growth inhibition. Since the physical interactions of NK cells with cryptococci and tumor cells were dissimilar, we were interested in whether this affected the kinetics of binding of NK cells to the targets. To determine the time required for maximal binding of NK cells to cryptococci, NWN or Percoll fraction 1 and 2 cells were incubated with $C$. neoformans targets for various periods of time before counting the numbers of NK cell- $C$. neoformans conjugates. The maximum numbers of effector cell-Cryptococcus conjugates were observed at $2 \mathrm{~h}$ after mixing either NWN or Percoll fraction 1 and 2 splenic cells with the cryptococcal target cells, and the percentages of conjugates after the 2-h incubation with each of the effector cell populations remained relatively constant throughout the 16-h assay (Fig. 5). As was expected, higher percentages of effector cell- $C$. neoformans conjugates were observed when the effector cell populations were greatly enriched for NK cells (Percoll fraction 1 and 2 cells) than when the NWN cell populations which contained fewer NK cells were used as effector cells (Fig. 5).

In parallel with the binding assays, we assessed the abilities of the Percoll fraction 1 and 2 cells to inhibit the growth of $C$. neoformans at various times after mixing the effector and target cells. The numbers of cryptococcal CFU obtained at each time period for cryptococci incubated in medium alone (cryptococcal control) and for cryptococci incubated with the effector cells (test) are shown in Fig. 6. There were no significant differences in the CFU counts between the test and control situations until $6 \mathrm{~h}$ of incubation. At that time, the samples which contained the Percoll fraction 1 and 2 effector cells displayed a $26 \%$ inhibition in cryptococcal growth compared with the controls $(P<0.01$; Fig. 6). With longer incubation times, the differences in the CFU of the controls and test samples became greater, and by the end of the 20-h assay period, a maximum of $81 \%$ inhibition of cryptococcal growth was observed (Fig. 6).

Effects of 2-ME and DMSO on NK cell binding to cryptococci and on NK cell-mediated cryptococcal growth inhibition. Binding of NK cells to tumor cell targets has been shown to be prevented by $2-\mathrm{ME}$, which presumably functions by reducing important disulfide bonds required for stable binding (16). Binding is also inhibited by DMSO, a reagent which destabilizes protein-lipid interactions in the plane of the 

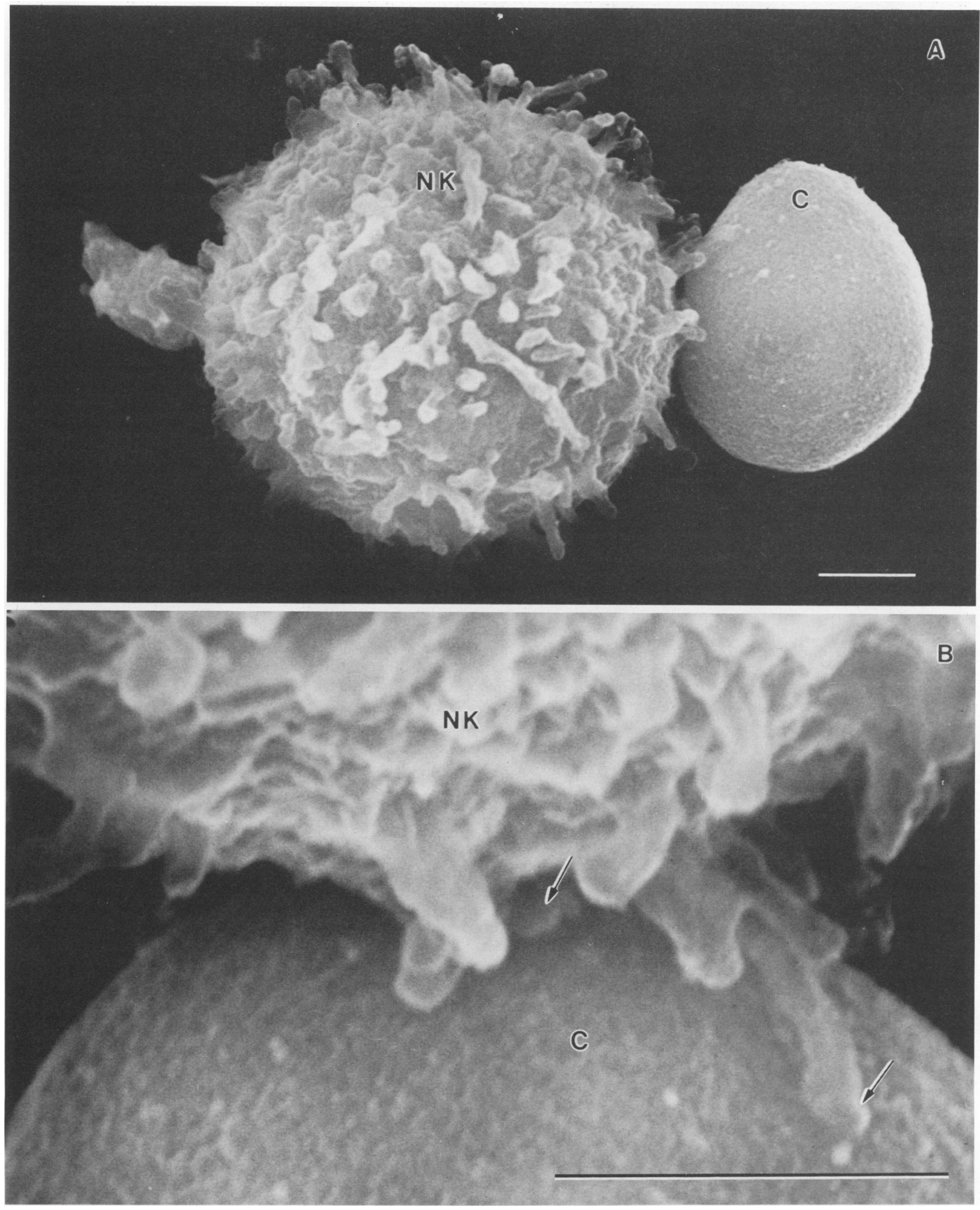

FIG. 1. SEMs of an NK cell-C. neoformans conjugate. Percoll fraction 1 and 2 cells were incubated with cryptococci for $12 \mathrm{~h}$ prior to preparing the specimen for electron microscopy. Arrows, Microvilli in intimate contact with the cryptococcal cell surface. Bars, $1 \mu \mathrm{m}$. 

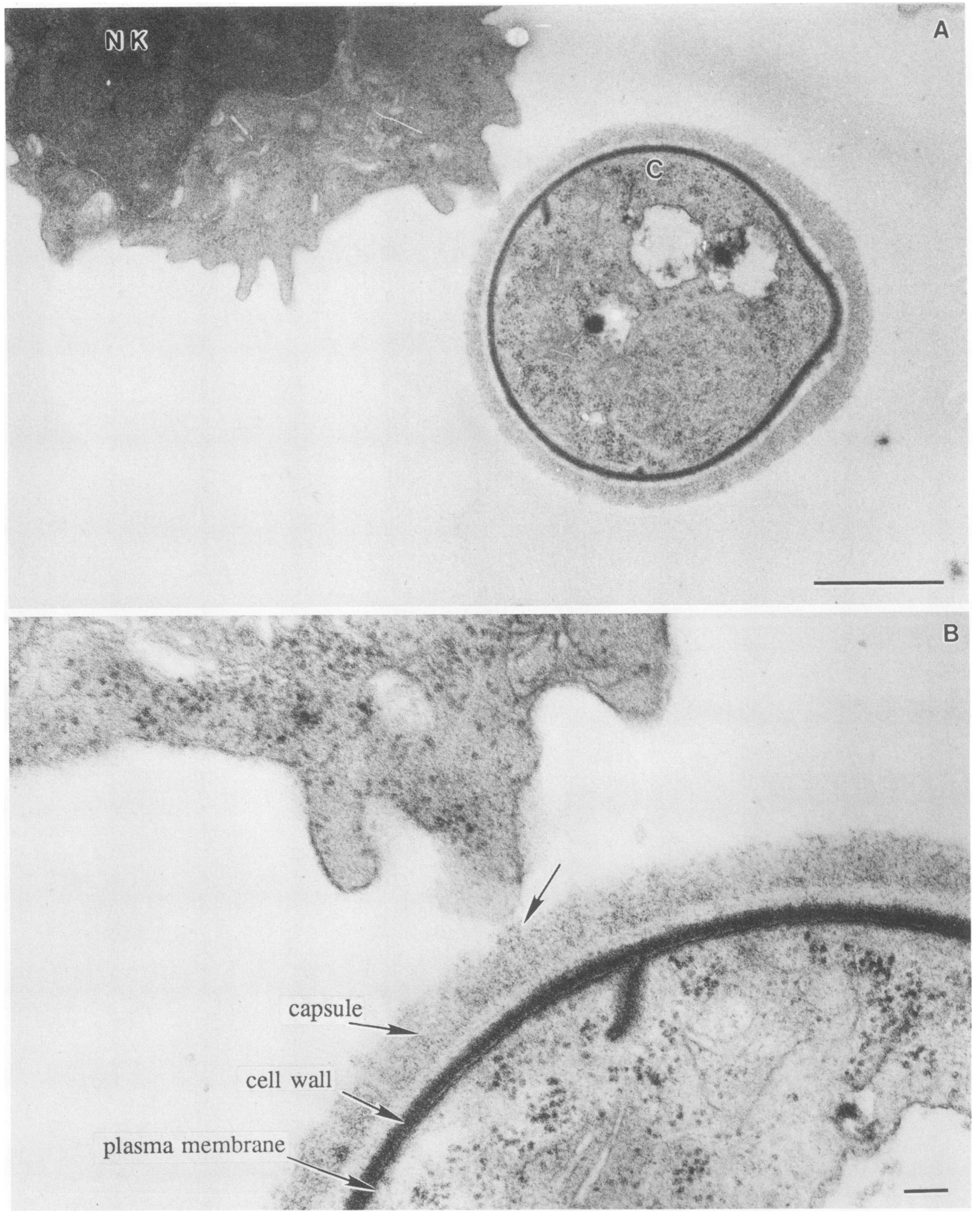

FIG. 2. TEMs of a 100-nm section through an NK cell-C. neoformans conjugate. Percoll-fractionated splenic LGL were incubated with cryptococcal target cells for $12 \mathrm{~h}$ before the specimen was prepared for TEM. Arrow, Tubular structure at the end of NK cell microvillus. Bars, $1 \mu \mathrm{m}(\mathrm{A})$ and $100 \mathrm{~nm}(\mathrm{~B})$. 


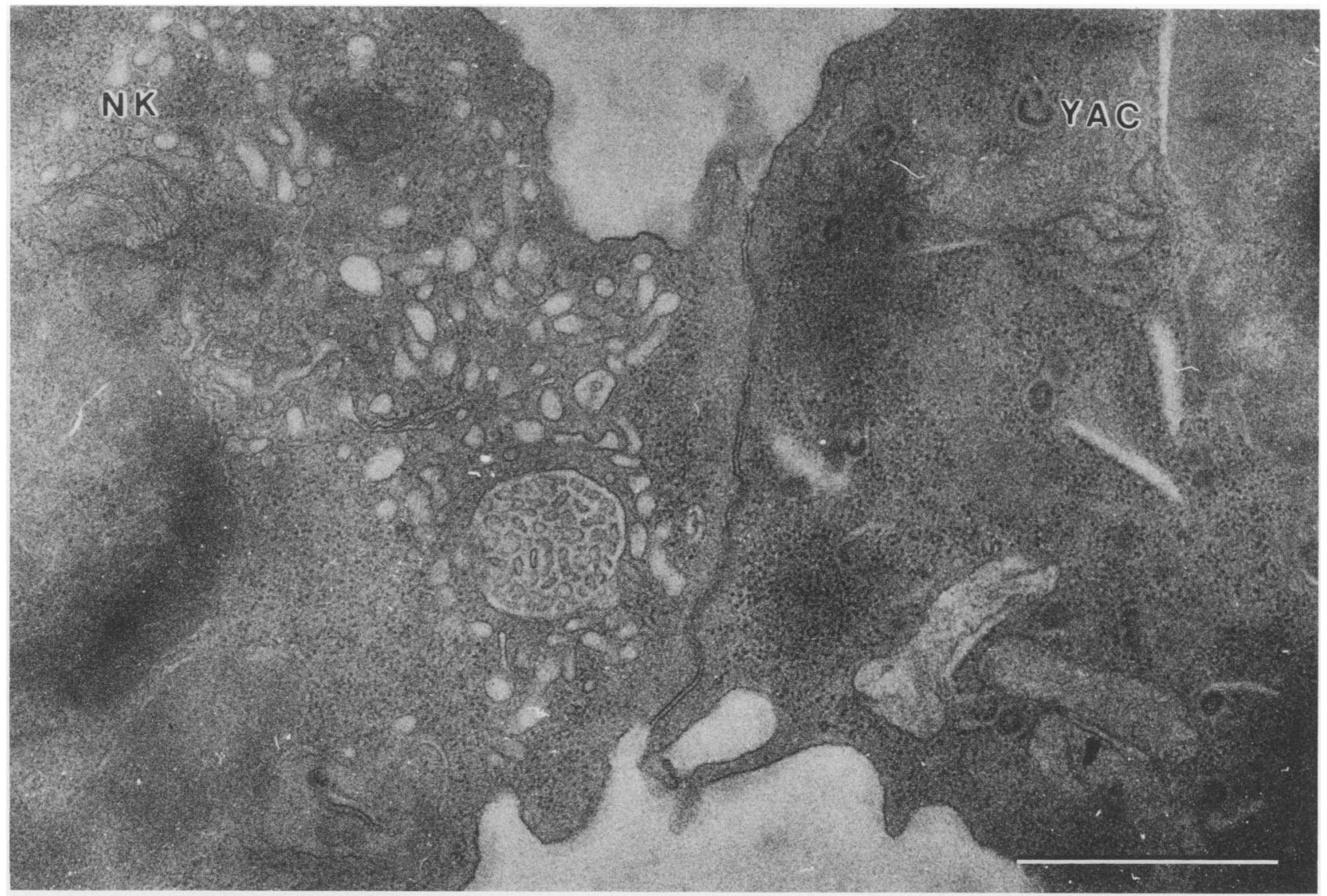

FIG. 3. TEM of a 100-nm section through an NK cell-YAC-1 tumor cell conjugate. Percoll-fractionated splenic LGL were incubated with YAC-1 cells for $1 \mathrm{~h}$ before the specimen was prepared for TEM. Bar, $1 \mu \mathrm{m}$.

membrane, resulting in disorganization and weakening of the membrane receptor-binding capacity $(16,31)$. To assess the importance of these two pharmacologic reagents in binding and growth inhibition of cryptococcal targets compared with their effects in binding and lysis of YAC-1 tumor cell targets, the reagents were added at two different concentrations to the respective assays. In the presence of $5 \mathrm{mM} 2-\mathrm{ME}$, the percentages of conjugates formed by NK cells binding to $C$. neoformans (Fig. 7A) or YAC-1 (Fig. 7B) targets were significantly reduced from the RPMI control levels $(P<$ $0.001)$. NK cell-mediated cryptococcal growth inhibition and lysis of YAC-1 targets were also significantly diminished when $5 \mathrm{mM} 2-\mathrm{ME}$ was added to the assays at the onset $(P<$ 0.005; Fig. 7C and D, respectively). In contrast, $1 \mathrm{mM} 2-\mathrm{ME}$ or 0.1 or $0.01 \mathrm{M}$ DMSO did not affect conjugate formation with the cryptococcal targets (Fig. 7A); however, $1 \mathrm{mM}$ 2-ME and 0.1 M DMSO, but not 0.01 M DMSO, did significantly reduce NK cell binding to YAC-1 targets $(P<$ 0.05; Fig. 7B). Even though the level of NK cell-Cryptococcus conjugate formation was not affected demonstratively by $1 \mathrm{mM} 2-\mathrm{ME}$ or the two concentrations of DMSO used, inhibition of cryptococcal growth was significantly reduced from the control level under those conditions $(P<0.02$; Fig. 7C). As would be expected since conjugate formation between NK cells and YAC-1 targets was diminished by 2-ME and $0.1 \mathrm{M}$ DMSO, lysis of the YAC-1 cells was also reduced $(P<0.05$; Fig. 7D)

To ascertain the effects of 2-ME and DMSO on preformed
NK cell- $C$. neoformans conjugates, experiments similar to those described above were performed; however, in this case, the variable reagents were added after $2 \mathrm{~h}$ of incubation to the cryptococcal assays and after $1 \mathrm{~h}$ of incubation to the tumor cell assays. With one exception, neither 2-ME nor DMSO when added to the assays after conjugates had formed caused the conjugates to dissociate. This was evident by the fact that the percentages of conjugates with either the cryptococcal targets or the YAC-1 cells were the same in the presence and absence of these reagents (Fig. 8A and $\mathrm{B}$ ), except when $5 \mathrm{mM} 2-\mathrm{ME}$ was added to conjugates of $\mathrm{NK}$ cells and YAC- 1 cells $(P<0.05$; Fig. 8B). The $5 \mathrm{mM}$ concentration of 2-ME caused a slight but significant reduction in the percentage of conjugates. Although the conjugates were not disrupted by these two pharmacologic agents, inhibition of cryptococcal growth was significantly reduced from the control level when $5 \mathrm{mM} 2-\mathrm{ME}$ or 0.1 or $0.01 \mathrm{M}$ DMSO was added after conjugate formation $(P<0.001$; Fig. $8 \mathrm{C})$. The percentage of specific lysis of YAC-1 targets was significantly diminished from the control level when 1 or 5 $\mathrm{mM} 2-\mathrm{ME}$ or 0.1 or $0.01 \mathrm{M}$ DMSO was added $1 \mathrm{~h}$ into the 4-h ${ }^{51} \mathrm{Cr}$ release assays $(P<0.02$; Fig. 8D).

Requirement for an intact cytoskeletal network for NK cell binding to cryptococci. Actin filaments, as well as microtubules, are components of the cytoskeletal network of the NK cells that must be intact for NK cells to lyse tumor target cells. The actin filaments, 6- to 8-nm helical structures formed by the polymerization of actin and found near the 

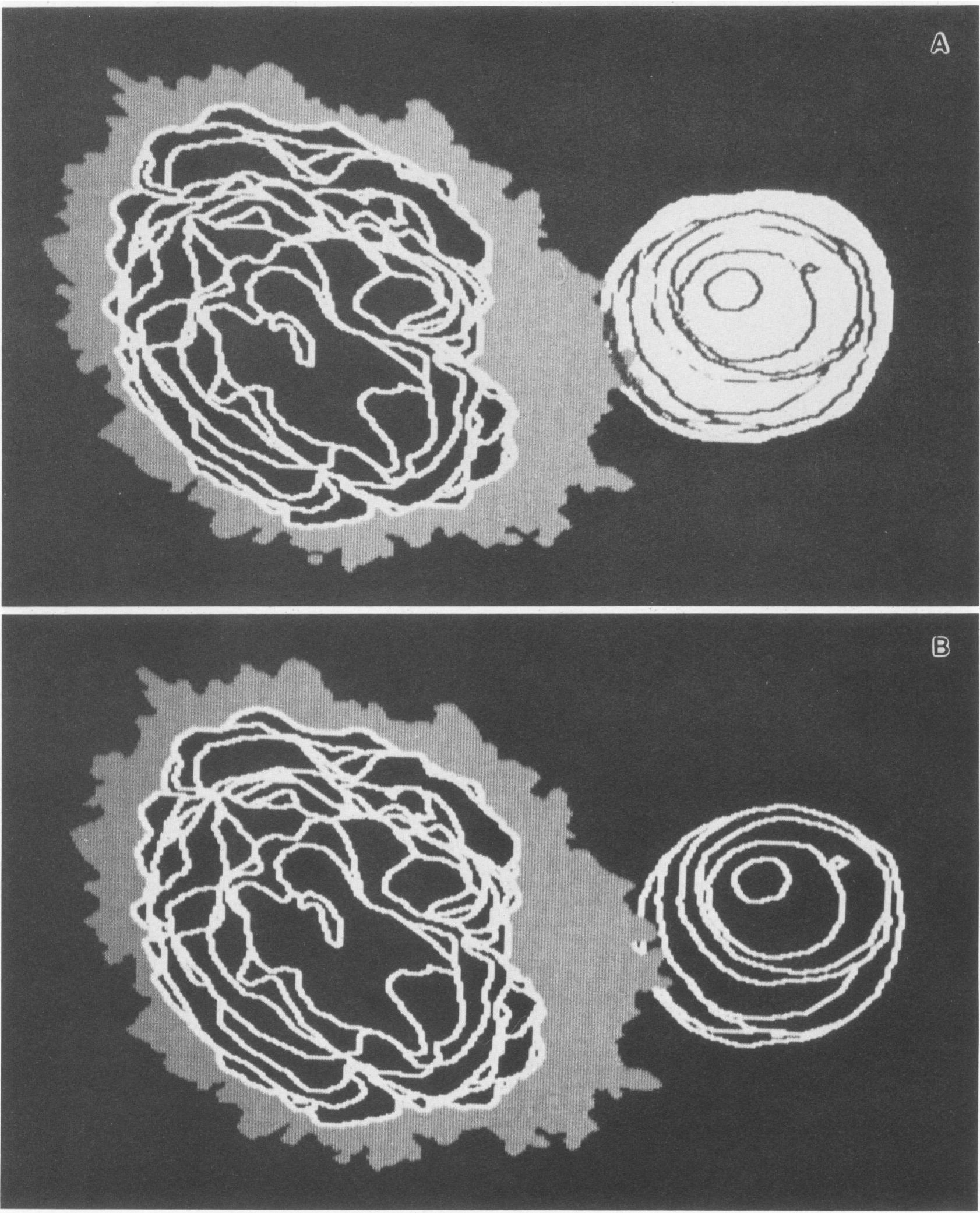

FIG. 4. (A) Three-dimensional reconstruction of an NK cell-C. neoformans conjugate prepared from electron micrographs of 100 -nm serial sections of the complete conjugate. (B) Same three-dimensional reconstruction with the outline of the cryptococcal capsule deleted. Percoll-fractionated splenic LGL were incubated with cryptococcal target cells for $12 \mathrm{~h}$ before preparation for TEM. The NK cell structures shown are the cytoplasm (gray) and nucleus (black outlined in white). The $C$. neoformans structures shown in panel A are the capsule surface (white) and the cell wall (black); in panel B, the cell wall of $C$. neoformans is outlined in white and the capsule has been removed. 


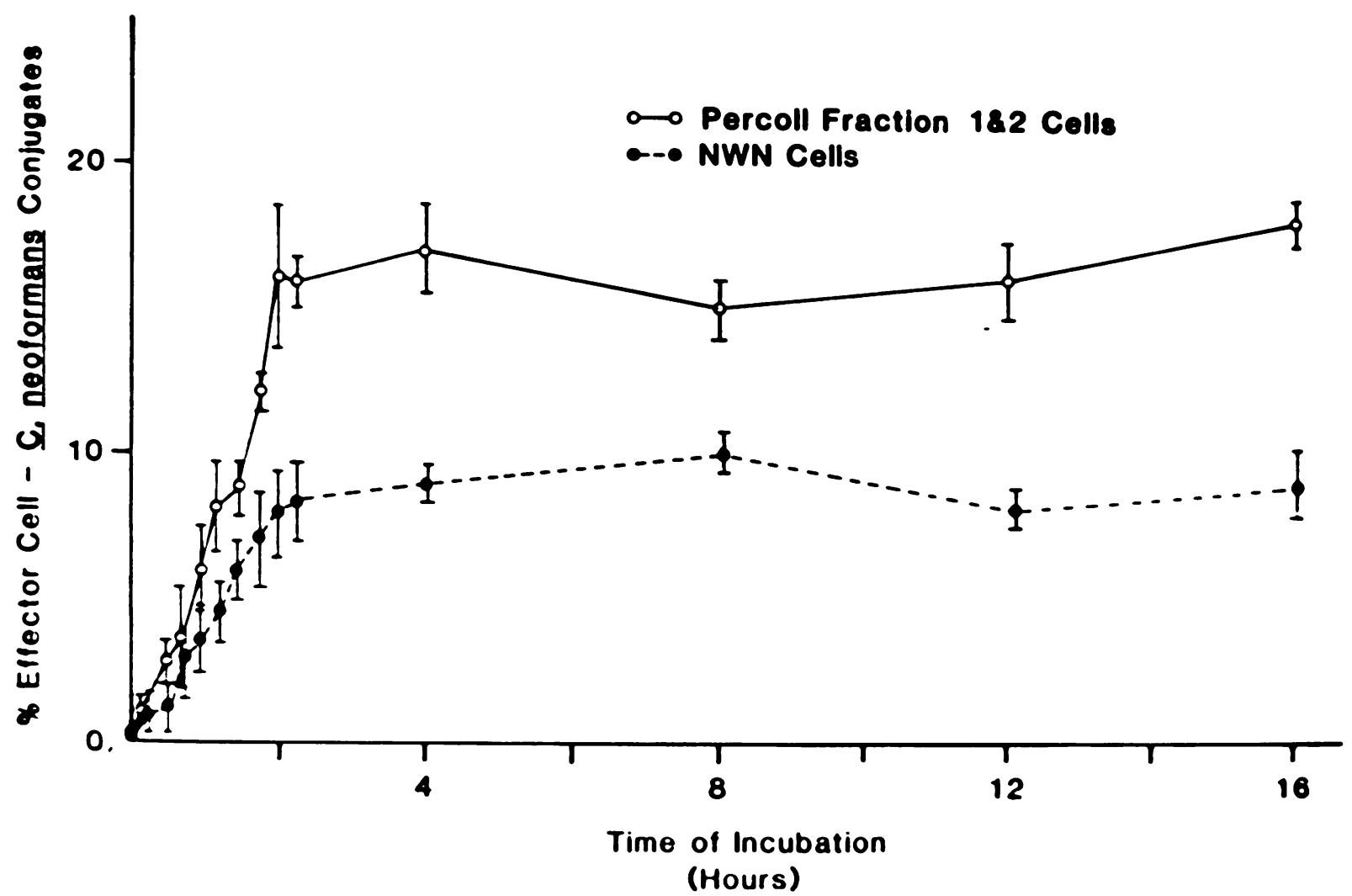

FIG. 5. Kinetics of effector cell-C. neoformans conjugate formation. NWN or Percoll fraction 1 and 2 splenic effector cells were incubated with cryptococci at an effector-cell-to-Cryptococcus ratio of 2:1 for various time periods before determining the percentage of conjugates. Bars, Standard errors of the means for quadruplicate samples. Data are representative of two experiments.

plasma membrane, have been shown to be required for binding of lymphoid effector cells including $\mathrm{NK}$ cells to tissue-type target cells $(3,18,19,29,31)$. Cytochalasins B and $\mathrm{D}$ are reagents that inhibit actin filament elongation $(7,9$, 23) and therefore can be used to assess a need for these cytoskeletal structures in cell-cell interactions. To determine the requirements for actin filaments in NK cell interactions with cryptococci target cells, cytochalasin B or D was added to the cryptococcal growth inhibition or, for comparison, to the ${ }^{51} \mathrm{Cr}$ release assays, at the onset of the assays. At a concentration of $6 \mu \mathrm{g} / \mathrm{ml}$, cytochalasin B significantly reduced NK cell binding to cryptococci $(P<0.001$, compared with the $0.12 \%$ DMSO control; Fig. 9A) and to YAC-1 targets $(P<0.001$, compared with the DMSO control; Fig. 9B). Furthermore, $6 \mu \mathrm{g}$ of cytochalasin B per ml abrogated cryptococcal growth inhibition (Fig. 9C) and cytolysis of YAC-1 cells (Fig. 9D). In contrast, cytochalasin B at a concentration of $1 \mu \mathrm{g} / \mathrm{ml}$ did not affect binding of NK cells to either target (Fig. 9A and B) but did significantly reduce cryptococcal growth inhibition $(P<0.001$, compared with the DMSO control; Fig. 9C) and lysis of YAC-1 cells $(P<$ 0.02, compared with the DMSO control; Fig. 9D).

Since cytochalasin D has been shown to be more effective in inhibiting actin polymerization than cytochalasin B (7), we repeated the experiments by using $1,2,4$, and $6 \mu \mathrm{g}$ of cytochalasin D per ml. The results with cytochalasin D were similar to those obtained with cytochalasin B. Cytochalasin $\mathrm{D}$ at $1 \mu \mathrm{g} / \mathrm{ml}$ did not affect NK cell binding to cryptococci but reduced growth inhibition; however, the other three concentrations significantly reduced both parameters (data not shown). All four concentrations of cytochalasin D significantly diminished conjugate formation and lysis of YAC-1 cells compared with the controls (data not shown).

Two control groups were included in the experiments in which cytochalasin B or D was used. One was a positive control that consisted of the cells incubated in CM designated RPMI (Fig. 9), and the second control was a diluent control which contained cells incubated in $0.12 \%$ DMSO diluted in CM (Fig. 9). The latter control was included and used for statistical analyses because the cytochalasin B or D was dissolved in DMSO and diluted in CM, giving a final concentration of $0.12 \%$ DMSO. The results obtained in the two different control situations were similar, indicating that $0.12 \%$ DMSO alone had no detectable effects (Fig. 9).

\section{DISCUSSION}

The studies presented in this paper focused on the binding interactions of murine NK cells with cryptococcal target cells. Considering the structural and chemical differences between cryptococcal cells and the more common tissuetype targets of NK cells, it might be anticipated that there would be differences in the NK cell interactions with the two types of target cells. By comparing several aspects of NK cell interactions with $C$. neoformans and YAC- 1 tumor cell targets, we demonstrated some differences in the binding interactions between the two types of target cells, but we also observed some similarities.

Our first consideration was in the physical nature of the interactions of NK cells with Cryptococcus and YAC-1 


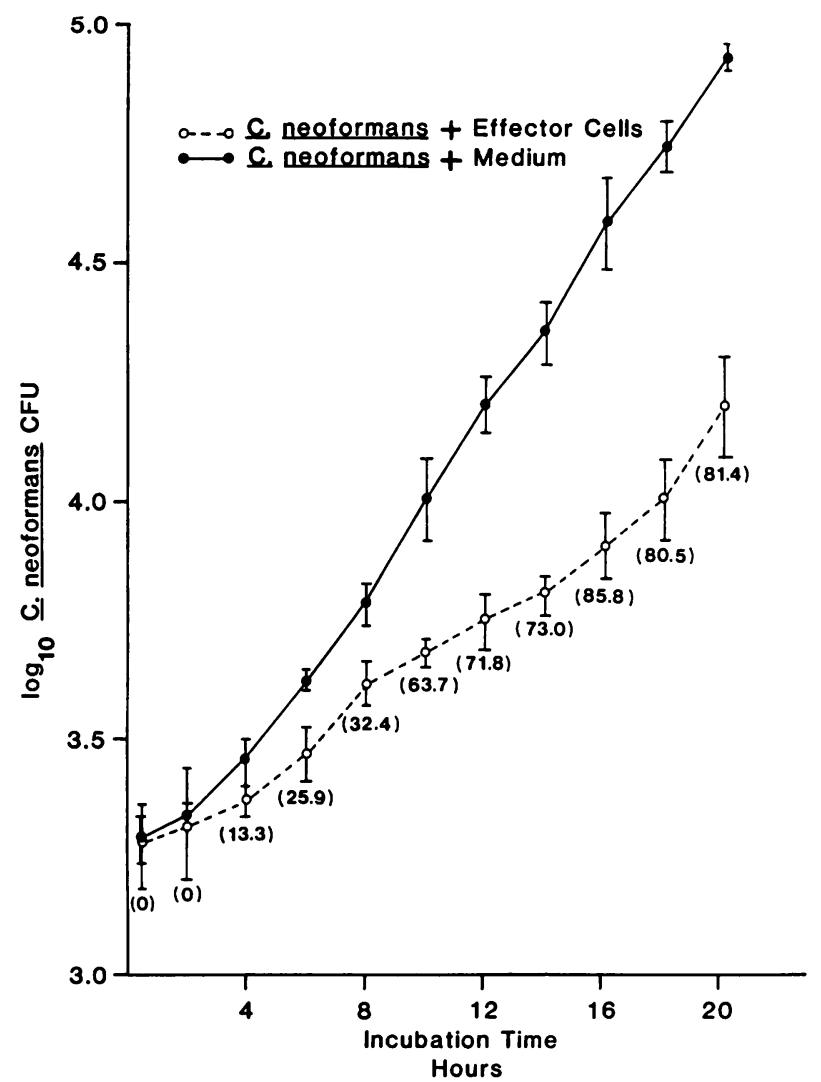

FIG. 6. Kinetics of $C$. neoformans growth inhibition. Percoll fraction 1 and 2 splenic effector cells were incubated with cryptococci at an effector-to-target cell ratio of 100:1 for various time periods before determining the percentage of cryptococcal growth inhibition. Numbers in parentheses indicate the percent inhibition of cryptococcal growth. Bars, Standard errors of the means for quadruplicate samples. Data are representative of two experiments.

tumor cell targets. To examine the physical interactions of NK cells with these targets, we chose to use Percoll fraction 1 and 2 effector cell populations from mouse spleens because we have previously shown (i) that similar cell populations are enriched concomitantly for NK cells and effector cells that bind to cryptococci and (ii) that the cells binding to cryptococci have characteristics of NK cells (27). SEMs and TEMs as well as three-dimensional reconstructions of conjugates which were prepared by incubating murine splenic Percoll fraction 1 and 2 cells with cryptococci show that the NK cells attach to cryptococcal cells through numerous microvilli. This is in contrast to the appearance of the binding region between NK cells and tumor target cells, where there was a broad interdigitating area of membranemembrane interaction observed by us (Fig. 3) and others (32). The dissimilarities in the physical attachment of NK cells to $C$. neoformans target cells compared with the attachment to tumor targets is not unexpected when one considers that the exterior layer of the cryptococcal cells consists of a thick mantle of polysaccharide covering a rigid cell wall as opposed to the outer surface of the tumor cell target, which is a thin, flexible cytoplasmic membrane. In the TEMs, we also observed NK cell microvilli physically associated with the surface of the cryptococcal cells, and in some cases, linear structures were seen at the contact site. It is not precisely clear how these physical interactions might

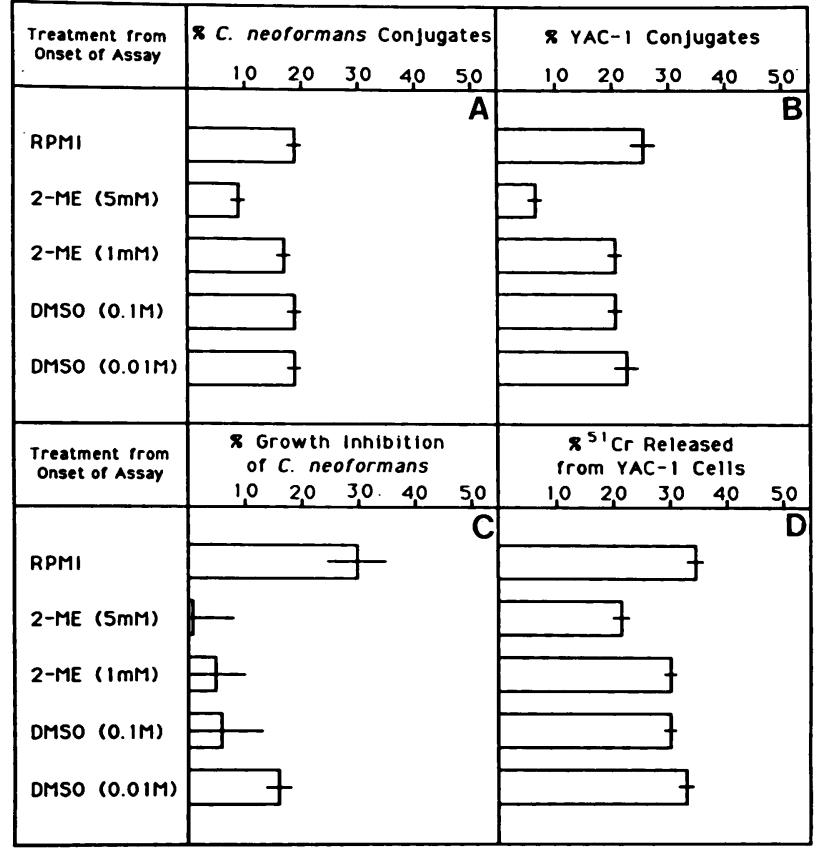

FIG. 7. Effects of 2-ME and DMSO on NK cell-C. neoformans interactions when added at the onset of the assays. Murine splenic NWN cells were used as effector cells in the NK cell-target cell binding assays, cryptococcal growth inhibition assay, and ${ }^{51} \mathrm{Cr}$ release assay in either CM (RPMI) or CM plus the designated reagent added at the time of mixing of the effector and target cells (onset of the assays). Bars, Means \pm the standard errors of the means of quadruplicate samples. Data are representative of three experiments.

impact on the subsequent stages of NK cell-mediated cryptococcal growth inhibition, but since the initial binding interactions between effector and target cells are important in signal transduction in other models $(15,36)$, one might expect the binding interactions to influence NK cell-mediated cryptococcal growth inhibition.

The differences in the physical characteristics of cryptococci and the type of binding interactions between NK cells and cryptococcal target cells suggested to us that the time required for association might be protracted in comparison to NK-tumor cell binding. We found that maximum NK cell-C. neoformans conjugate formation was achieved after 2 $h$ of incubation with either NWN or Percoll fraction 1 and 2 splenic cells as the source of NK cells. This is in contrast to $20 \mathrm{~min}$, which is required to obtain the maximum number of NK cell-YAC-1 conjugates (32; our unpublished data). Thus, the structural differences between the cryptococci and the tumor cells appear to influence the time required for NK cells to form stable conjugates with the target cells, with considerably more time being required for stable binding of NK cells to the encapsulated, cell wall-bound cryptococci than necessary for stable binding to membrane-bound tumor targets. The percentages of NK cell- $C$. neoformans conjugates did not change significantly when the incubation time was increased beyond $2 \mathrm{~h}$, suggesting that either the conjugates did not dissociate or that continuous recycling was occurring. We favor the latter explanation since NK cells have been shown to detach from tumor cell targets and move to other target cells after inflicting a lethal hit (35). Furthermore, the observation that the percentage of cryptococcal 


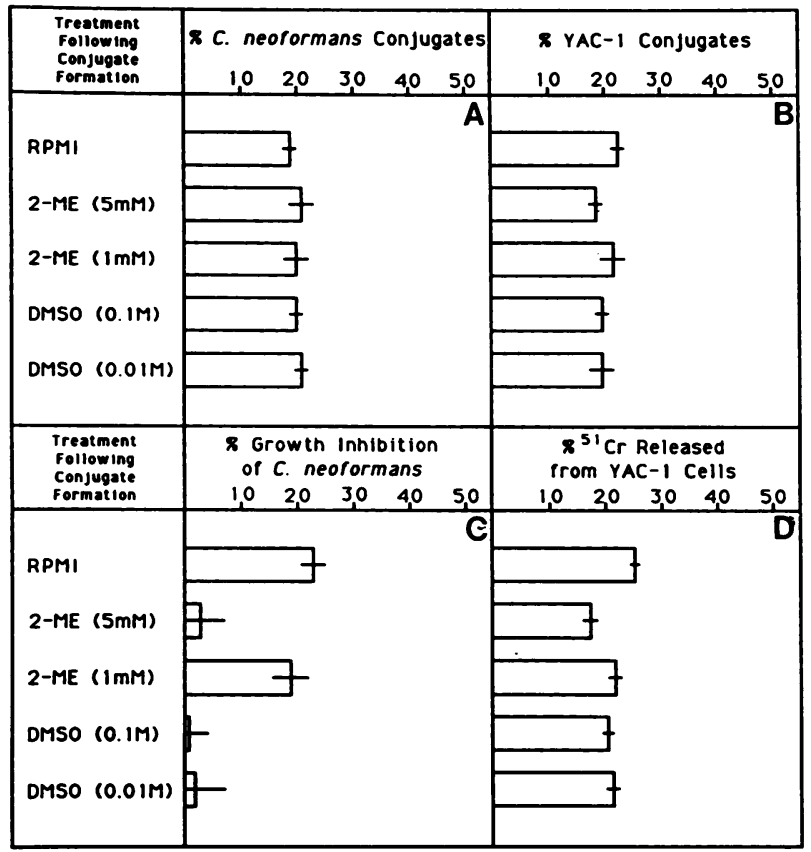

FIG. 8. Effects of 2-ME and DMSO on NK cell-C. neoformans interactions when added after conjugates had formed. Murine splenic NWN cells were used as effector cells in the NK cell-target cell binding assays, cryptococcal growth inhibition assay, and ${ }^{51} \mathrm{Cr}$ release assay in either CM (RPMI) or CM containing the designated reagent which was added after $2 \mathrm{~h}$ of incubation to the NK cell- $C$. neoformans mixtures and after $1 \mathrm{~h}$ of incubation to the NK cellYAC-1 cell mixtures. Bars, Means \pm the standard errors of the means of quadruplicate samples. Data are representative of three experiments.

growth inhibition increases as the incubation time is extended (26\% growth inhibition at $6 \mathrm{~h}$ compared with $86 \%$ at $16 \mathrm{~h})$ supports the concept that the NK cells in the mixture recycle from one $C$. neoformans to another, thereby damaging more yeast cells as time progresses.

As was expected, the percentages of NK cell- $C$. neoformans conjugates were higher when Percoll fraction 1 and 2 cells were used as effectors than when NWN cells were the effectors. Since the Percoll fraction 1 and 2 cell populations were more enriched for NK cells than were the NWN cell populations, the data provide further evidence that NK cells are the effector cells binding to the cryptococci in both populations.

Earlier observations that blocking of binding of NK cells to cryptococci abrogated growth inhibition suggested that binding of NK cells to cryptococci is an essential prerequisite to cryptococcal cell damage $(12,27)$. If binding is essential for NK cell-induced damage to cryptococci, then one would expect the time required to detect an adverse effect on the cryptococcal targets (inhibition of growth) would be longer than the time required for maximum conjugate formation. In fact, that was the case. A minimum of $6 \mathrm{~h}$ in culture or $4 \mathrm{~h}$ beyond the time of maximum conjugate formation was necessary before cryptococcal growth inhibition could be detected. These data confirm that binding precedes growth inhibition in the NK cell- $C$. neoformans interaction.

The kinetics data also demonstrate that the overall process of NK cell-mediated damage to cryptococci is protracted

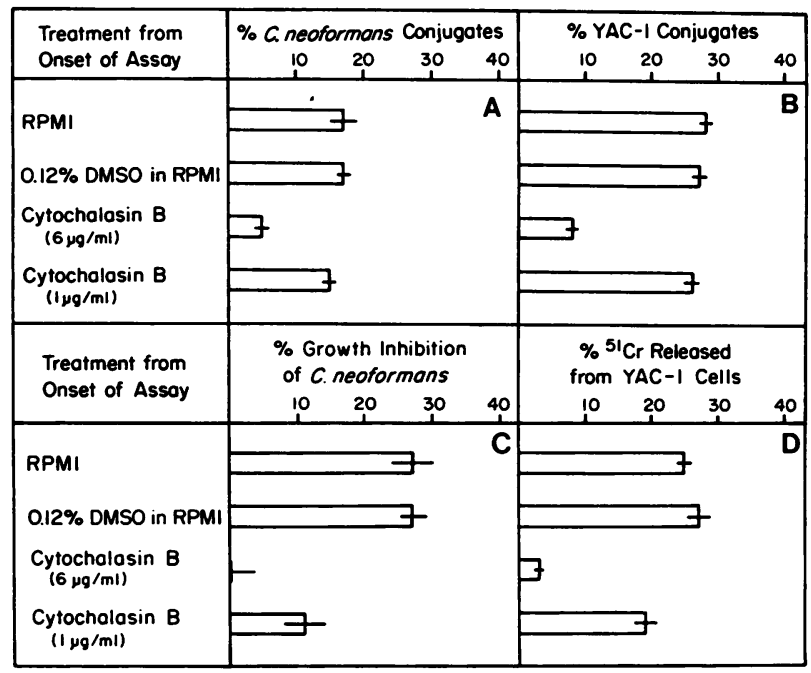

FIG. 9. Effects of cytochalasin B on NK cell-C. neoformans interactions. Murine splenic NWN cells were used as effector cells in the NK cell-target cell binding assays, cryptococcal growth inhibition assay, and ${ }^{51} \mathrm{Cr}$ release assay in either CM (RPMI), CM with $0.12 \%$ DMSO, or CM with $0.12 \%$ DMSO and 1 or $6 \mu \mathrm{g}$ of cytochalasin B per ml. Bars, Means \pm standard errors of the means of quadruplicate samples. Data are representative of three experiments.

when contrasted to the process of NK cell-mediated lysis of tumor targets $(2 \mathrm{~h}$ for binding to cryptococci and an additional 2 to $4 \mathrm{~h}$ for growth inhibition compared with $20 \mathrm{~min}$ for binding to tumor cells and an additional 5 to $10 \mathrm{~min}$ for lysis) (32). Several factors may contribute to the delay in cryptococcal growth inhibition compared with tumor cell lysis. One factor is the retarded binding of NK cells to cryptococcal targets compared with tumor cell targets. A second factor is possibly a delay in the signaling of NK cells by the cryptococcal target. It is well established that binding of NK cells to sensitive target cells stimulates rearrangement of NK cell organelles, which prepares the effector cells for cytotoxic component secretion and granule exocytosis $(2,4,6,19,21)$. We have previously demonstrated that binding of $C$. neoformans to NK cells results in a delayed rearrangement of the NK cell microtubule-organizing centers compared with that observed with tumor targets (9a). Therefore, this delay in rearrangement of NK cell organelles is probably reflected in an extended time for the total process of NK cell-mediated inhibition of cryptococcal growth compared with the time required for tumor cell lysis. A third factor is the slowness with which the reactive components of the NK cells damage the cryptococcal yeast cells compared with the time required to lyse the tumor target cells (13). Earlier results show that granules isolated from rat NK cells required $1 \mathrm{~h}$ of contact to maximally inhibit the growth of cryptococci, whereas the same preparations of granules had a measurable effect on YAC-1 cells within 20 min (13). Components of NK cells other than the granules are also effective in limiting the growth of cryptococci, and their inhibitory effects are not immediate (13). These combined delays would be expected to result in the overall extended period of time for NK cell-mediated damage to cryptococcal cells compared with NK cell killing of tumor targets, as we have demonstrated experimentally.

Requirements for disulfide bonding and membrane and 
cytoskeletal integrity in NK cell binding to cryptococcal cells were assessed by adding various pharmacologic agents to the NK cell- $C$. neoformans assays or, for comparison, to the NK cell-YAC-1 cell assays, at the onset of the assays or after conjugates had formed. From such studies, it was apparent that disulfide bonding plays a role in binding, since reduction of disulfide bonds with $5 \mathrm{mM} 2-\mathrm{ME}$ reduced NK cell conjugate formation with both target cells, abrogated cryptococcal growth inhibition, and significantly diminished YAC-1 cell lysis. Disulfide bonding could be important beyond the binding stage as well, since $1 \mathrm{mM} 2-\mathrm{ME}$ did not affect binding of NK cells to cryptococci but did significantly diminish the percentage of cryptococcal growth inhibition. With human NK cells and tumor targets, others have shown that 2-ME influences postbinding stages (16). Deem and Targan (5) have reported that 2-ME almost completely inhibits lysis of K562 targets by NKCF, a soluble cytolytic factor produced by $\mathrm{NK}$ cells. In addition, $2-\mathrm{ME}$ partially blocks NK cell-mediated lysis of K562 cells during the killer cell-independent phase (5). The Deem and Targan data indicate that disulfide bonding is essential for events in the lethal hit stage in human NK cell-mediated tumor cell lysis (5). In contrast to the effects of the lower concentration (1 $\mathrm{mM}$ ) of 2-ME on the NK cell-cryptococcal cell system, that concentration of 2-ME slightly, but significantly, reduced NK cell-mediated binding and lysis of YAC-1 targets. From this, one might deduce that the postbinding stages in the NK cell-cryptococcal cell system are more sensitive to reduction of disulfide bonding than are similar stages in NK cellmediated tumor cell lysis. The conclusion that disulfide bonding is necessary during a stage beyond the binding stage in NK cell-induced inhibition of cryptococcal growth is also supported by the observation that $5 \mathrm{mM} 2-\mathrm{ME}$ added after conjugate formation did not disrupt the conjugates but did significantly reduce the level of cryptococcal growth inhibition. Since $1 \mathrm{mM} 2-\mathrm{ME}$ had no effect on binding or inhibition of cryptococcal growth when added after $2 \mathrm{~h}$, a sufficient time for maximum conjugate formation, but did have a measurable effect on growth inhibition when added at the time of mixing the effector cells with the cryptococcal target cells, it is possible that $2-\mathrm{ME}$ affects a very early postbinding event. Hiserodt et al. (16) and Deem and Targan (5) have shown with the human NK cell-K562 model that 2-ME blocks a very early substage of the lethal hit. Further investigations are needed to determine the exact stage in the NK cell- $C$. neoformans interaction that is affected by $1 \mathrm{mM}$ 2-ME.

We found that when $5 \mathrm{mM} 2-\mathrm{ME}$ was added to the ${ }^{51} \mathrm{Cr}$ release assay with YAC-1 targets after conjugates had formed, there was a slight but significant disruption of conjugates. This is in contrast to findings with human NK cells in which $5 \mathrm{mM}$ 2-ME did not dissociate preformed NK cell conjugates with K562 targets (16). Thus, it possible that disulfide bonding is more important for stable binding of murine NK cells to YAC-1 tumor cell targets than for binding of human NK cells to their targets. Although $1 \mathrm{mM}$ 2-ME did not affect preformed conjugates of NK and YAC-1 cells, it did significantly reduce the percentage of target cell lysis, indicating that disulfide bonding is important in postbinding processes leading to lysis of YAC-1 cells. This may be the first report of a dose response effect with 2-ME on the lysis of tumor targets by NK cells, since we have been unable to find a published report in which two concentrations of 2-ME were used with either K562 targets or YAC-1 cells.

By destabilizing the plasma membrane with DMSO, it has been shown that membrane integrity is another factor that affects binding of both murine and human NK cells to their appropriate tumor cell targets $(16,31)$. When YAC-1 cells were used as targets in the NK cell assays with DMSO, we found, just as did Roder et al. (31), that 0.1 M DMSO minimally but significantly inhibited binding of the NK cells to YAC-1 cells (Fig. 7B) and reduced the percent lysis of YAC-1 cells (Fig. 7D). In contrast, $0.1 \mathrm{M}$ DMSO did not affect NK cell- $C$. neoformans conjugate formation, suggesting that the slight effect DMSO had on the NK cells did not alter the NK cell ability to bind to the yeast target. The lower concentration of DMSO $(0.01 \mathrm{M})$ did not alter binding of NK cells to cryptococci; however, DMSO at 0.1 and $0.01 \mathrm{M}$ concentrations blocked the ability of NK cells to damage $C$. neoformans cells. From our studies, it is not clear whether these rather low concentrations of DMSO affected the NK cells, thus preventing them from damaging cryptococcal cells or whether DMSO had a protective effect on the cryptococcal cells which reduced NK cell-mediated damage. It is possible that the higher concentration of $1 \mathrm{M} \mathrm{DMSO}$ used by Roder et al. (31) which more dramatically reduced conjugate formation between murine NK cells and YAC-1 cells would have been sufficient to prevent conjugate formation with cryptococcal cells. We attempted to examine the effects of $1 \mathrm{M}$ DMSO on NK cell- $C$. neoformans interactions and found that $1 \mathrm{M}$ DMSO inhibited the growth of cryptococci in the control cultures, making the resulting data from the effector cell and $C$. neoformans mixtures meaningless.

Disulfide bonding and membrane integrity could be reduced to levels that affected NK-YAC-1 cell interactions without affecting NK cell-C. neoformans binding interactions. Therefore, one might postulate that NK cell binding to cryptococci relies more on carbohydrate-carbohydrate interactions between the NK cell membrane glycoproteins and the cryptococcal polysaccharides or mannoprotein than does NK cell binding to YAC-1 tumor cells, which may be more dependent upon protein-protein interactions. In contrast to binding, postbinding events, such as the signaling of NK cells by $C$. neoformans to release cytotoxic substances or the lethal hit, were more sensitive to pharmacologic reagents that disrupted disulfide bonding or altered membrane integrity. Since the effective transmission of signals through receptor-ligand interactions requires intact membranes, one might expect the results we obtained. It is likely that the mode of $C$. neoformans binding to NK cells is less efficient in signal transduction than is the mode of YAC-1 cell binding to NK cells, so that, as we have shown, slight effects induced by DMSO on the NK cell are more critical to postbinding events in the NK cell-C. neoformans model than in the NK-tumor cell model.

Binding of NK cells to cryptococci is dependent on intact actin filaments, since agents such as cytochalasin B or D at sufficient concentrations to effectively inhibit actin filament elongation blocked binding of NK cells to cryptococci. Actin filaments are known to be present in the microvilli of cells, provide some mechanical support for the microvilli, and contribute to movement of the cell (1), so actin filaments might be expected to be important in movement and attachment of the NK cell microvilli to the cryptococcal cells. We observed that $1 \mu \mathrm{g}$ of cytochalasin B per ml did not significantly inhibit binding of NK cells to cryptococci or YAC-1 targets but did significantly reduce cryptococcal growth inhibition and lysis of YAC-1 cells. The extent of inhibition of actin filament elongation rate depends upon the concentration of cytochalasin B (23); therefore, $1 \mu \mathrm{g}$ of cytochalasin $\mathrm{B}$ per $\mathrm{ml}$ would be less efficient at slowing the rate of actin 
filament elongation than the $6-\mu \mathrm{g} / \mathrm{ml}$ concentration. With this concept in mind, our data could be interpreted in two ways. It is possible that in the presence of $1 \mu \mathrm{g}$ of cytochalasin B per $\mathrm{ml}$ there was sufficient elongation of actin filaments to allow a single round of binding of NK cells to target cells, but not sufficient for NK cells to recycle and bind to other targets. Under such conditions, the percentage of conjugates would be expected to be equivalent to the percentage of conjugates in controls as we observed, but the effects on the target cells (percent growth inhibition or percent lysis) at the end of the assay would be reduced because the NK cells could not recycle and damage additional targets. On the other hand, it is possible that actin filament elongation is necessary for binding of NK cells to target cells and for postbinding events as well, but minimal elongation will allow binding to occur, whereas the postbinding events require extensive actin filament elongation. Our data do not permit us to distinguish between these two possibilities.

In summary, the physical characteristics of the binding of murine NK cells to the encapsulated, cell wall-bound cryptococci are different from those of the binding of membranebound tumor target cells. Tips of numerous microvilli of the NK cells form the attachment points to the cryptococcal targets, and the microvilli may penetrate the mantle of capsular polysaccharide to associate with the cryptococcal cell wall. In contrast, NK cells bind to tumor targets through broader membrane-membrane interactions. Despite the differences in the physical nature of NK cell binding to fungal and tumor targets, NK cells must be able to form actin filaments to conjugate with either target cell. More time is required for NK cells to form stable conjugates with cryptococcal cells than with tumor targets, and the time NK cells need to damage cryptococci is protracted when compared with the tumor cell lysis. Disulfide bonding may be involved in the binding of NK cells to cryptococci just as it is in conjugate formation between NK cells and tumor targets. A slight disruption of membrane integrity does not appear to affect NK cell binding to cryptococci as it does in the binding of NK cells to tumor cells. Considered together, our data confirm that binding of the NK cell to the $C$. neoformans target cell is prerequisite to the stage in which the cryptococcal target cells are damaged.

\section{ACKNOWLEDGMENTS}

This work was supported by Public Health Service grant AI-18895 from the National Institute of Allergy and Infectious Diseases.

The electron microscopy was performed at the Samuel Roberts Noble Electron Microscopy Laboratory, Norman, Okla. The assistance of Bill Chissoe, Diane Hurd, and Natalie Hoshaw in preparation of the electron micrographs and three-dimensional reconstructions is greatly appreciated.

\section{REFERENCES}

1. Alberts, B., D. Bray, J. Lewis, M. Raff, K. Roberts, and J. D. Watson. 1983. Molecular biology of the cell, p. 549-609. Garland Publishing, New York.

2. Carpen, O., I. Virtanen, V. Lehto, and E. Saksela. 1983. Polarization of NK cell cytoskeleton upon conjugation with sensitive target cells. J. Immunol. 131:2695-2698.

3. Carpen, O., I. Virtanen, and E. Saksela. 1981. The cytotoxic activity of human natural killer cells requires an intact secretory apparatus. Cell. Immunol. 58:97-106.

4. Carpen, O., I. Virtanen, and E. Saksela. 1982. Ultrastructure of human natural killer cells: nature of the cytolytic contacts in relation to cellular secretion. J. Immunol. 128:2691-2697.

5. Deem, R. L., and S. R. Targan. 1985. Analysis of sequential substages of the natural killer cell lethal hit. Adv. Exp. Med.
Biol. 184:239-254.

6. Dennert, G., A. Kupfer, C. G. Anderson, and S. J. Singer. 1985. Reorientation of the Golgi apparatus and the microtubule organizing center: is it a means to polarize cell-mediated cytotoxicity? Adv. Exp. Med. Biol. 184:83-93.

7. Flanagan, M. D., and S. Lin. 1980 . Cytochalasins block actin filament elongation by binding to high affinity sites associated with F-actin. J. Biol. Chem. 255:835-838.

8. Galey, F. R., and S. E. G. Nilsson. 1966. A new method for transferring sections from the liquid surface of a trough through staining solutions to the supporting film of a grid. J. Ultrastruct. Res. 14:405-410.

9. Goddette, D. W., and C. Frieden. 1986. Actin polymerization. J. Biol. Chem. 261:15974-15980.

9a.Hidore, M. R., T. W. Mislan, and J. W. Murphy. 1991. Responses of murine natural killer cells to binding of the fungal target Cryptococcus neoformans. Infect. Immun. 59:1489-1499.

10. Hidore, M. R., and J. W. Murphy. 1986. Correlation of natural killer cell activity and clearance of Cryptococcus neoformans from mice after adoptive transfer of splenic nylon wool nonadherent cells. Infect. Immun. 51:547-555.

11. Hidore, M. R., and J. W. Murphy. 1986. Natural cellular resistance of beige mice against Cryptococcus neoformans. J. Immunol. 137:3624-3631.

12. Hidore, M. R., and J. W. Murphy. 1989. Murine natural killer cell interactions with a fungal target, Cryptococcus neoformans. Infect. Immun. 57:1990-1997.

13. Hidore, M. R., N. Nabavi, C. W. Reynolds, P. A. Henkart, and J. W. Murphy. 1990. Cytoplasmic components of natural killer cells inhibit the growth of Cryptococcus neoformans. J. Leukocyte Biol. 45:15-26.

14. Hiserodt, J. C., and T. F. Beals. 1985. Ultrastructural analysis of human natural killer cell-target cell interactions leading to target cell lysis, p. 195-204. In R. B. Herberman and D. M. Callewaert (ed.), Mechanisms of cytotoxicity by NK cells. Academic Press, Orlando, Fla.

15. Hiserodt, J. C., L. J. Britvan, and S. R. Targen. 1982. Characterization of the cytolytic reaction mechanism of the human natural killer (NK) lymphocyte: resolution of binding, programming, and killer cell-independent steps. J. Immunol. 129:17821787.

16. Hiserodt, J. C., L. J. Britvan, and S. R. Targan. 1982. Differential effects of various pharmacologic agents on the cytolytic reaction mechanism of the human natural killer lymphocyte: further resolution of programming for lysis and KCIL into discrete stages. J. Immunol. 129:2266-2270.

17. Julius, M. H., E. Simpson, and L. A. Herzenberg. 1973. A rapid method for isolation of functional thymus-derived lymphocytes. Eur. J. Immunol. 3:645-649.

18. Kalina, M., and N. Hollander. 1975. The effect of cytochalasin B on effector-target cell interaction. Quantitative and ultrastructural study. Immunology 29:709-717.

19. Katz, P., A. M. Zaytoun, and J. H. Lee, Jr. 1982. Mechanisms of human cell-mediated cytotoxicity. III. Dependence of natural killing on microtubule and microfilament integrity. J. Immunol. 129:2816-2825.

20. Kiessling, R. E., E. Klein, and W. Wigzell. 1975. "Natural" killer cells in the mouse. I. Cytotoxic cells with specificity for mouse Moloney leukemia cells. Specificity and distribution according to phenotype. Eur. J. Immunol. 5:112-117.

21. Kupfer, A., G. Dennert, and S. J. Singer. 1983. Polarization of the Golgi apparatus and microtubule-organizing center within cloned natural killer cells bound to their targets. Proc. Natl. Acad. Sci. USA 80:7224-7228.

22. Luini, W., D. Baraschi, S. Alberti, A. Aleotti, and A. Tagliabue. 1981. Morphological characterization of a cell population responsible for natural killer activity. Immunology 43:663-668.

23. MacLean-Fletcher, S., and T. D. Pollard. 1980. Mechanism of action of cytochalasin B on actin. Cell 20:329-341.

24. Murphy, J. W. 1989. Natural host resistance mechanisms against systemic mycotic agents, p. 149-184. In C. W. Reynolds and R. H. Wiltrout (ed.), Functions of the natural immune system. Plenum Publishing Corp., New York. 
25. Murphy, J. W., and G. C. Cozad. 1972. Immunological unresponsiveness induced by cryptococcal capsular polysaccharide assayed by the hemolytic plaque technique. Infect. Immun. 5:896-901.

26. Murphy, J. W., and D. O. McDaniel. 1982. In vitro reactivity of natural killer (NK) cells against Cryptococcus neoformans. J. Immunol. 128:1577-1583.

27. Nabavi, N., and J. W. Murphy. 1985. In vitro binding of natural killer cells to Cryptococcus neoformans targets. Infect. Immun. 50:50-57.

28. Ortaldo, J. R., and C. W. Reynolds. 1987. Natural killer activity: definition of a function rather than a cell type. J. Immunol. 138:4545-4546.

29. Quan, P.-C., T. Ishizaka, and B. R. Bloom. 1982. Studies on the mechanism of NK cell lysis. J. Immunol. 126:1786-1791.

30. Reynolds, E. 1963. The use of lead at a high $\mathrm{pH}$ as an electronopaque stain in electron microscopy. J. Cell Biol. 17:208-213.

31. Roder, J. C., S. Argov, M. Klein, C. Petersson, R. Kiessling, K. Anderson, and M. Hansson. 1980. Target-effector cell interaction in the natural killer cell system. V. Energy requirements, membrane integrity, and the possible involvement of lysosomal enzymes. Immunology 40:107-116.

32. Roder, J. C., R. Kiessling, P. Biberfeld, and B. Andersson. 1978 Target-effector interaction in the natural killer (NK) cell system. II. The isolation of NK cells and studies on the mechanism of killing. J. Immunol. 121:2509-2517.

33. Spurr, A. R. 1969. A low-viscosity epoxy resin embedding medium for electron microscopy. J. Ultrastruct. Res. 26:31-43.

34. Targen, S. R., and R. L. Deem. 1985. NK-target cell interactions in binding, triggering, programming, and lethal hit of NK cytotoxicity, p. 155-172. In R. B. Herberman and D. M. Callewaert (ed.), Mechanisms of cytotoxicity by NK cells. Academic Press, Orlando, Fla.

35. Timonen, T., J. R. Ortaldo, and R. B. Herberman. 1982. Analysis by a single cell cytotoxicity assay of natural killer (NK) cell frequencies among human large granular lymphocytes and of the effects of interferon on their activity. J. Immunol. 128:2514-2521.

36. Trinchieri, G. 1989. Biology of natural killer cells. Adv. Immunol. 47:187-375.

37. Ullberg, M., and M. Jondal. 1981. Recycling and target binding capacity of human killer cells. J. Exp. Med. 153:615-628. 